\title{
Development and Validation of Survey Questionnaire \& Experimental Data - A Systematical Review-based Statistical Approach
}

\author{
Architha Aithal* \& P. S. Aithal** \\ *Intern, PharmD, Srinivas College of Pharmacy, Mangalore, India \\ OrchID: 0000-0003-2361-5166; E-mail: aithalarchitha@gmail.com \\ **Professor, College of Management \& Commerce, Srinivas University, Mangalore, India \\ OrcidID: 0000-0002-4691-8736; E-mail: psaithal@gmail.com
}

Area/Section: Social Science \& Health Science.

Type of the Paper: Review based Analysis.

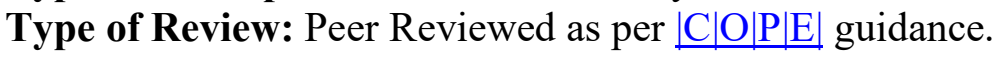

Indexed in: OpenAIRE.

DOI: http://doi.org/10.5281/zenodo.4179499

Google Scholar Citation: IJMTS.

\section{How to Cite this Paper:}

Architha Aithal \& Aithal P. S. (2020). Development and Validation of Survey Questionnaire \& Experimental Data - A Systematical Review-based Statistical Approach. International Journal of Management, Technology, and Social Sciences (IJMTS), 5(2), 233251. DOI: http://doi.org/10.5281/zenodo.4179499

International Journal of Management, Technology, and Social Sciences (IJMTS) A Refereed International Journal of Srinivas University, India.

(C) With Author.

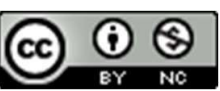

This work is licensed under a Creative Commons Attribution-Non-Commercial 4.0 International License subject to proper citation to the publication source of the work.

Disclaimer: The scholarly papers as reviewed and published by the Srinivas Publications (S.P.), India are the views and opinions of their respective authors and are not the views or opinions of the SP. The SP disclaims of any harm or loss caused due to the published content to any party. 


\title{
Development and Validation of Survey Questionnaire \& Experimental Data - A Systematical Review-based Statistical Approach
}

\author{
Architha Aithal* \& P. S. Aithal** \\ *Intern, PharmD, Srinivas College of Pharmacy, Mangalore, India \\ OrchID: 0000-0003-2361-5166; E-mail: aithalarchitha@gmail.com \\ **Professor, College of Management \& Commerce, Srinivas University, Mangalore, India \\ OrcidID: 0000-0002-4691-8736; E-mail: psaithal@gmail.com
}

\begin{abstract}
In quantitative research methodology, the empirical research method is finding importance due to its effectiveness in carrying out research in social sciences, business management, and health sciences. The empirical research method contains the procedure of developing a model to find the relationship between different variables identified in a problem. Based on developing hypotheses and testing hypotheses, one can examine and improve the model to explain realworld phenomena. The empirical research method consists of using a survey-based questionnaire to collect the data to identify and interrelate variables present in the problem. It is a comparatively difficult task to design and develop an effective, efficient, and psychometrically perfect questionnaire to be used for research data collection in empirical and clinical research settings. This paper provides a reference on guidelines and framework for developing suitable questionnaires for use in social sciences, business management, medical, and paramedical research with a special emphasis on various stages of questionnaire preparation, preliminary questionnaire testing, and validation (reliability \& validity) of the questionnaire using a number of statistical methods. The paper throws light on data collection and analysis stages before the finalization of the developed model for testing hypotheses in empirical research by providing guidelines for the design, development, and translation of questionnaires for application in the above-mentioned research fields. The different types of validation processes required for cleaning the data by various measuring instruments in experimental research are also discussed for comparison. A framework is suggested to guide researchers through the various stages of questionnaire design, development, and improvement using suitable statistical methods to assess the reliability and validity of the questionnaire used in empirical research and validation of the data obtained in experimental research.
\end{abstract}

Keywords: Empirical research method, Questionnaire survey, Questionnaire design, Questionnaire preparation, Questionnaire testing, Validation (Reliability \& Validity) of questionnaire, Validation of experimental data

\section{INTRODUCTION :}

Research is a process of investigating answers to a question in a scientific and systematic manner by means of the formulation of the hypotheses, testing of the hypotheses by means of data collection on relevant constructs, analysis, and interpreting the results in a systematic way, and reaching the conclusions as a generalized solution. The main objectives of scholarly research are to get familiarity with a phenomenon, find out the association or independence of activities and to identify the characteristics of an individual or a group of activities, their relationships, and the frequency of occurrence. Depending on the objectives of the research, the research can be classified into exploratory research, experimental research, empirical research, conclusive research, descriptive research, and casual research [1-2].

Questionnaires based survey methods are widely used in social science, business management, and clinical research to collect quantitative data from consumers, customers, and patients. In medical and 
paramedical (clinical) research, the survey questionnaire is used to collect quantitative data and information from respondents including patients, their relatives, and health-care professionals. In clinical research, data and information of interest could range from observable information on physical findings to subjective evidence of the patients. A systematic questionnaire should be constructed for this purpose. While developing such a new questionnaire, the researcher may refer to or follow a preavailable questionnaire with the standard format from available literature references. This paper discusses the procedure of design and development of an empirical questionnaire and determining its reliability and consistency by validating it systematically using various statistical methods. The paper also provides an overview of the validation of experimental data obtained from research instruments for their reliability and consistency.

\section{SURVEY BASED EMPIRICAL RESEARCH :}

The survey based on an empirical research method consists of the identification of a problem, determining its affecting factors, finding their inter-relations by means of developing a preliminary model of the problem/system. The model can be tested scholarly by using an empirical survey research method. The block diagram, which interrelates various steps in the survey research method is shown in figure 1. The essential components of such survey methods are : (1) developing a preliminary model of the problem under consideration, (2) Identify the constructs of the problem, (3) Developing Hypotheses (4) Develop a questionnaire for hypothesis testing, (5) Preliminary Questionnaire testing, (6) Validation (Reliability \& Validity) of questionnaire, (7) Subsequent validation, (8) Determination of Sample size, (9) Sample collection through a questionnaire distribution, (10) Sample analysis using statistical methods, (11) Identifying acceptable hypothesis, and (12) Re-building the preliminary model as Final Model.

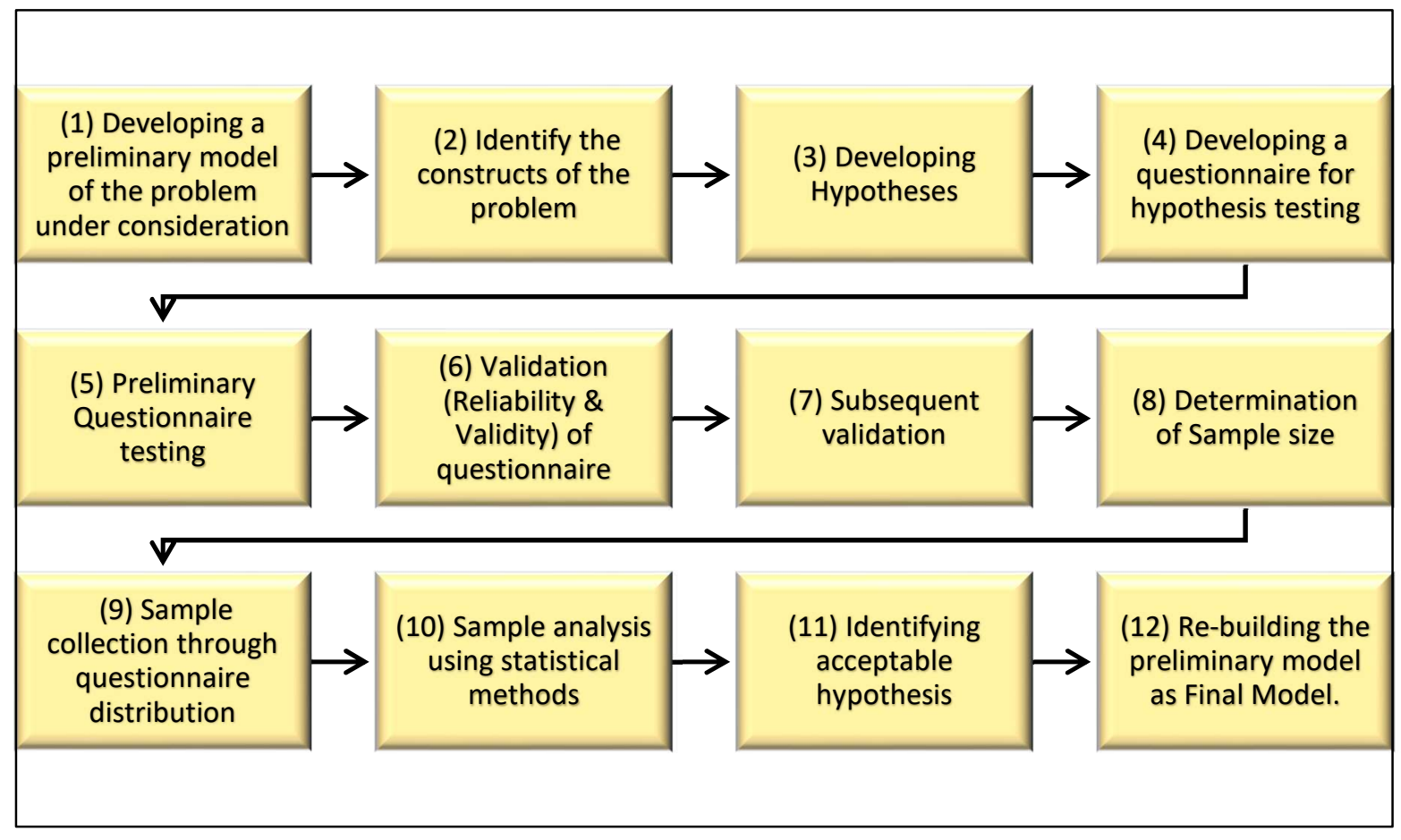

Fig. 1 : The block diagram which interrelates various steps in the survey research method

\section{REVIEW OF RELATED WORK :}

In a survey based empirical research, questionnaire planning, design, preparation, and validation are preliminary works of a researcher before administering it to identified respondents. Many research publications are available through Google scholar in different aspects related to it and some important scholarly publications related to various issues are listed in table 1. 
Table 1 : Some important scholarly publications in the related area

\begin{tabular}{|l|l|l|l|}
\hline S. No. & Topic & Issues & Reference \\
\hline 1 & Questionnaire survey & $\begin{array}{l}\text { The sample survey: Theory and } \\
\text { practice }\end{array}$ & $\begin{array}{l}\text { Warwick, D. P. et al. } \\
\text { (1975). [3] }\end{array}$ \\
\hline 2 & Questionnaire survey & Survey research & $\begin{array}{l}\text { Rossi, P. H., et al. (2013). } \\
\text { [4] }\end{array}$ \\
\hline 3 & Questionnaire design & A split questionnaire survey design & $\begin{array}{l}\text { Raghunathan, T. E., et al. } \\
\text { (1995). [5] }\end{array}$ \\
\hline 4 & Questionnaire design & Designing a questionnaire & $\begin{array}{l}\text { Ballinger, C., et al. } \\
\text { (1998). [6] }\end{array}$ \\
\hline 5 & Questionnaire design & $\begin{array}{l}\text { Questionnaire design: the good, the } \\
\text { bad and the pitfalls. }\end{array}$ & $\begin{array}{l}\text { Bee, D. T., et al. (2016). } \\
\text { [7] }\end{array}$ \\
\hline 6 & Questionnaire design & Methods for questionnaire design & $\begin{array}{l}\text { Oosterveld, P., et al. } \\
\text { (2019). [8] }\end{array}$ \\
\hline 7 & Questionnaire design & $\begin{array}{l}\text { Item placement for questionnaire } \\
\text { design for optimal reliability }\end{array}$ & $\begin{array}{l}\text { Kachroo, P., et al. (2018). } \\
\text { [9] }\end{array}$ \\
\hline 9 & Questionnaire design & Sampling and questionnaire design & $\begin{array}{l}\text { Sirakaya-Turk, E., et al. } \\
\text { (2017). [10] }\end{array}$ \\
\hline 10 & Questionnaire design & $\begin{array}{l}\text { Asking the Right Questions of the } \\
\text { Right People at the Right Time }\end{array}$ & $\begin{array}{l}\text { Moroney, W. F., et al. } \\
\text { (2019). [11] }\end{array}$ \\
\hline 11 & $\begin{array}{l}\text { Questionnaire design } \\
\text { preparation }\end{array}$ & $\begin{array}{l}\text { How to design a questionnaire } \\
\text { Yaddanapudi, S., et al. } \\
\text { (2019). [12] }\end{array}$ \\
\hline 12 & $\begin{array}{l}\text { Questionnaire } \\
\text { preparation }\end{array}$ & $\begin{array}{l}\text { Preparation of a questionnaire } \\
\text { according to Delphi method } \\
\text { questionnaire }\end{array}$ & $\begin{array}{l}\text { Riaño, C. E., et al. } \\
\text { (2015). [13] }\end{array}$ \\
\hline 13 & $\begin{array}{l}\text { Questionnaire } \\
\text { preparation }\end{array}$ & $\begin{array}{l}\text { Preparation of the split questionnaire } \\
\text { design approach }\end{array}$ & $\begin{array}{l}\text { Bovell-Benjamin, A. C., } \\
\text { et al (2009). [14] }\end{array}$ \\
\hline $\begin{array}{l}\text { Peytchev, A., et al. } \\
\text { (2017). [15] }\end{array}$ \\
\hline 14 \\
Questionnaire testing & $\begin{array}{l}\text { Overview of Questionnaire Design } \\
\text { and Testing }\end{array}$ & $\begin{array}{l}\text { de Jong, et al. (2018). } \\
\text { [16] }\end{array}$ \\
\hline
\end{tabular}

\section{PRELIMINARY MODEL DEVELOPMENT :}

The first step of any empirical research is the development of a preliminary model of the problem or system of consideration by identifying its various components, factors affecting performance, independent and dependent variables and considering their relations to each other. The preliminary model allows researchers to develop hypotheses for checking the model.

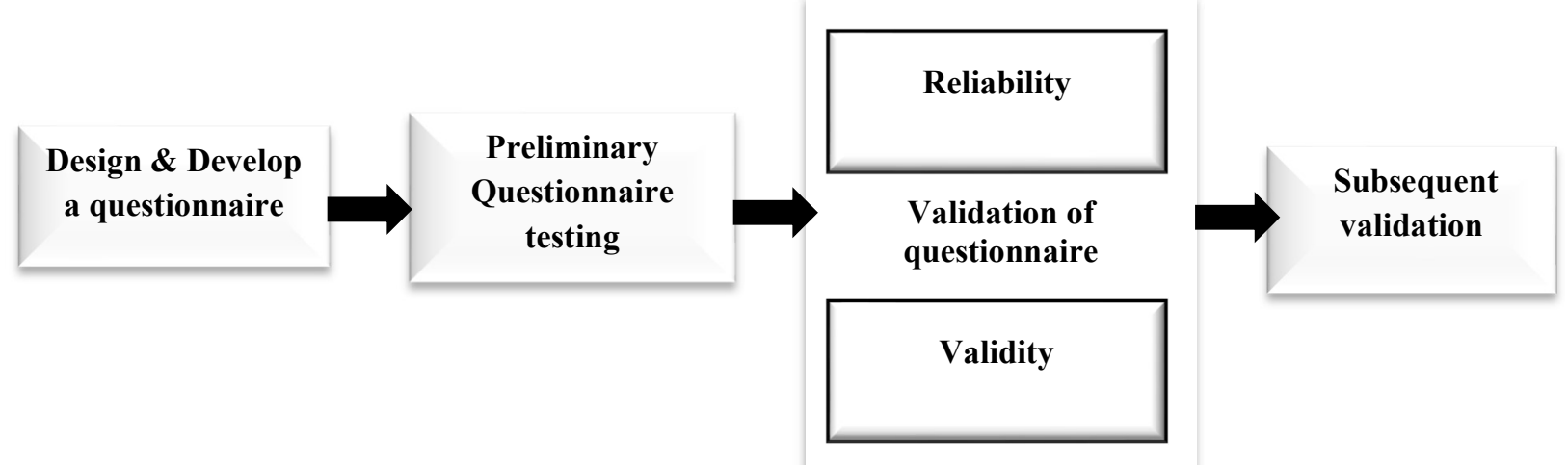

Fig. 2 : Questionnaire design \& development, reliability testing, \& validation stages

A questionnaire of a survey based research contains a set of questions also called items used for solving an identified research problem. These questions are developed with an aim at collecting different types of data related to demographic information, personal opinions, facts and attitudes, health related 
information, intangible information like feelings, taste, satisfaction, etc in certain tangible scale from respondents. The type of information required from the collected data of a questionnaire directly affects the design and development of the questionnaire. Qualitative questionnaires are used to collect data related to expository information and quantitative questionnaires are used to collect data to validate the previously generated hypothesis. There is a difference between survey and questionnaire based survey that in a survey, the surveyor collects information from respondents with standard answers, whereas in case of the Questionnaire based surveys, the respondents must be able to read the questions one by one and understand them perfectly before answering them well. Generally, two types of questionnaires are used in practice, depending on the nature of the research as structured and unstructured questionnaires. A structured questionnaire is used to collect quantitative data and is designed in such a way that it collects intended and specific information related to a problem. It can also be used to initiate formal inquiry, supplement data, and check data that have been previously collected, and also, to validate hypothesis. A structured questionnaire usually contains multiple choice based closed ended questions. An unstructured questionnaire is used to collect qualitative information using basic and branching questions which are mostly open-ended. Reliability and validity of items are two important qualities of a questionnaire used in empirical research. Depending on the design, development, and purpose of the questionnaire, the different checking and statistical methods are used to measure the reliability and validity of it, respectively [17].

The steps required in questionnaire development stage, reliability stage, and questionnaire validation stage are :

(1) Design \& develop a questionnaire using the Focus Group method

(2) Testing of questionnaire through a Pilot Testing method

(3) Determining the reliability of the questionnaire

(4) Determining Validity of questionnaire

(5) Subsequent validation

\section{DESIGN AND DEVELOPMENT OF QUESTIONNAIRE :}

Before constructing a systematic questionnaire to collect data samples related to a problem, the researcher should properly plan to imagine the ideal solution to the problem in hand and identify various issues and constructs related to the problem. The researcher can collect data samples related to the problem by using the Focus group method [18-19]. The various processes, issues, and constructs related to a problem in hand are :

\section{(1) Imagine the ideal solution to identified problem:}

For every research problem, one can imagine an ideal solution, which is actually a hypothetical solution and not possible to achieve in practice due to many constraints in real systems. However, imaging ideal solution is very important in research due to the fact that it will provide an opportunity to determine the research gap. Research gap is the practical (conceptual or experimental) gap between present existing solution and ideal imagined solution to a research problem. By means of systematic literature review and analysis, one can find out present status of the solution of a problem and hence the research gap. In research methodology, once the research gap of a problem is determined, the research agenda can be set by identifying the limitations of the researcher or research methods used in the proposed study [2021].

\section{(2) Identify the determinant issues and constructs:}

For every research problem, there are some determinant issues. Determinant issues are the primary issues of a problem related to a system (individuals or organizations) under consideration. These are major components of a system, including its environment [22-23]. For example, the determinant issues of a business model are Organizational Issues, Operational Issues, Employees Issues, Administrative issues, Customers Issues, Technological issues, Strategic Issues, Environmental \& Social issues, etc.

\section{(3) Determine the dimensionality of the construct:}

Construct is a tool used to facilitate understanding of ideas, people, organizations, events, objects or things belonging to a system. Constructs are used to identify various factors and elements of a system. Many constructs are multidimensional, meaning that they are composed of several related components. The constructs can be fully assessed by developing subscales to its components called factors and 
elements. Based on the importance of dimensions of constructs, weight will be assigned to the questions in the questionnaire.

\section{(4) Decide the format of the questionnaire for administration:}

The researchers should be clear on how the questionnaire be administered? Who will administer the questionnaire i.e., self-administered or administered by a research/clinical staff? The decision on administration of questionnaire depends partly on what it intends to measure in the empirical research. Depending upon the problem under consideration, some questionnaires are effective if a research/clinical staff asked the questions, whereas sometimes they may be more likely to respond truthfully if they are allowed to complete the questionnaire by themselves. In many cases, depending on the nature of information to be collected, it may be preferable to obtain objective ratings from the data collecting staff. On the other hand, if the respondents are to complete the questionnaire by themselves, then it should be developed in such a way that the readability level of the items in the questionnaire should be lowered.

\section{(5) Decide the format of various items in the Questionnaire:}

The researcher should decide whether the items in the questionnaire should be open ended or close ended? Questions that are open ended allow respondents to elaborate upon their responses. Open ended questions seek detailed answers and are best suited for situations in which researchers are wish to gather more information on a specific domain. But such responses are difficult to code and hence to summarize individuals' responses.

\section{(6) Closed end Questions should contain limited number of response options:}

Closed-ended questions are easier to administer and analyze. However, the respondent options may be influenced by the response options provided in the questionnaire. Close-ended questions may contain multiple-choice, Likert-type scales, true/false, or other close-ended formats. For using the collected data for subsequent statistical analyses, researchers should keep in mind that items should be scaled to generate sufficient variance among the intended respondents.

\section{(7) Questionnaire Items development Guidelines:}

Many guidelines are available for writing items. It includes suggestions like simple usage of language which is familiar to the target respondents. The items should be separated for affective questions and behavioural questions. Every item used in the questionnaire should be addressed to only one issue. Avoiding leading questions that are results in a biased response is required. Also, items, which attract the same response from everyone should not be included because it generates limited information about constructs being assessed. Some of the tips on writing open ended questions are summarized in table 2 [25].

Table 2 : Tips on writing open ended questions in the questionnaire [25]

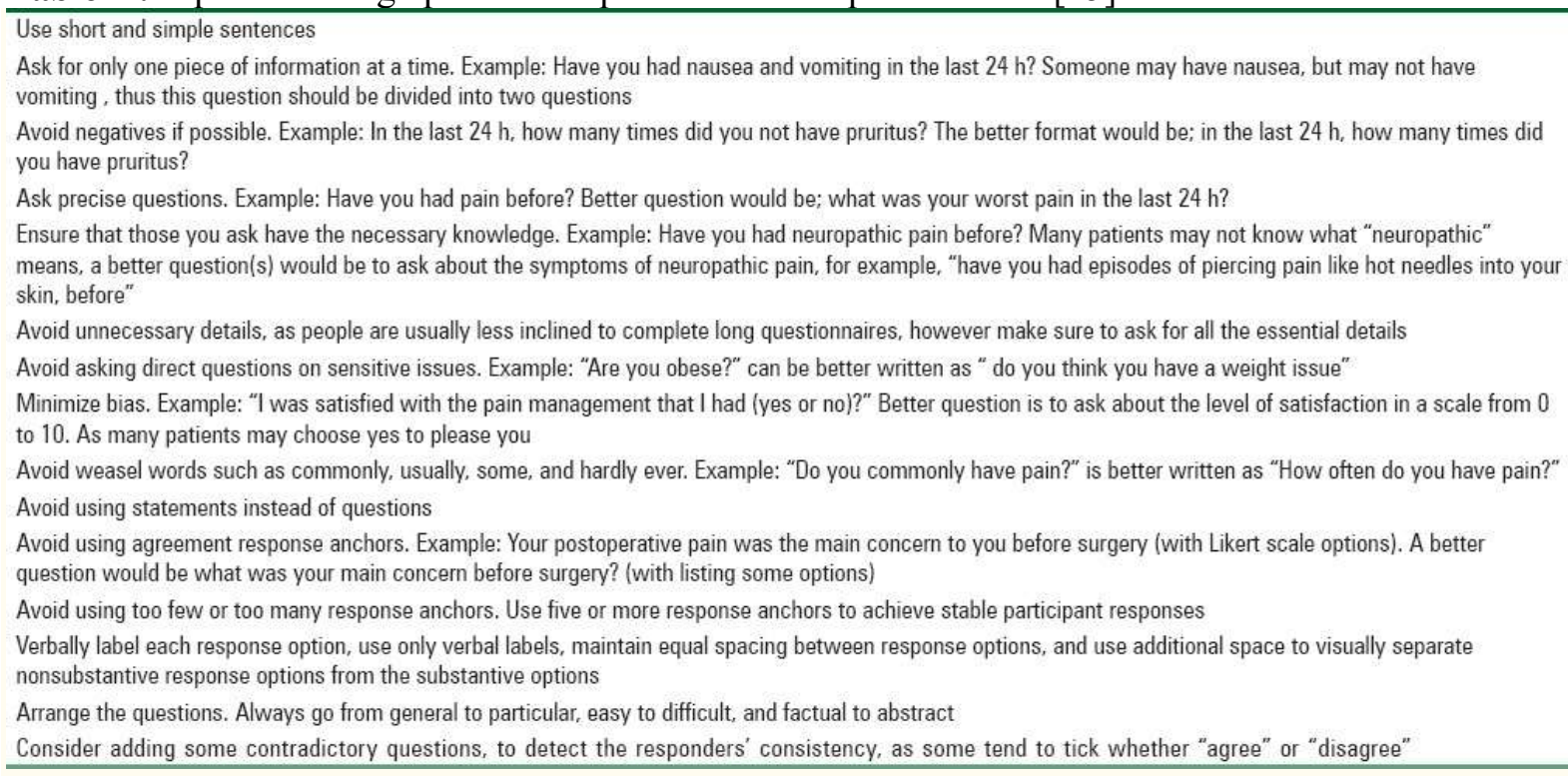

If researcher intended to include reverse-scored items (negatively worded items) in the questionnaire, extra care should be taken to avoid negative impact on the psychometric properties of scales. They 
should ensure that such reverse-scored items are properly interpreted by the respondents and reversescored items have similar psychometric properties as the regularly-scored items.

\section{(8) Minimize the length of questionnaire :}

Eliminate unnecessary questions to reduce the length of the questionnaire, even though there is no rule on the restriction on the number of questions. The length of the questionnaire should be in such a way that it should contain sufficient items to measure the construct of interest but should not fatigue or demotivate the respondent while filling the questionnaire. The questionnaire should be simple but it should help adequately to measure the constructs of interest with minimum measurement error. At the initial stage of developing questionnaire, a large set of items are used and many of them will be discarded during the refinement process.

\section{(9) Review and revise the initial set of items :}

The initial questionnaire developed by considering all constructs and intended measurement items should be reviewed by an expert reviewer in detail to avoid repetition and biased to a particular kind of analysis or interpretation. The review should also focus on eliminating any favourism to a particular subgroup of respondents. Other issues such as simplification, error free in construction, and grammatic errors should also be taken care in review stage.

\section{(10) Refining through Preliminary pilot testing :}

A preliminary pilot test should be conducted to check the effectiveness of the questionnaire before conducting a full-fledged final pilot test. Usually, the preliminary pilot test is administered on small set of respondents and the sample size is about 30 to 50 numbers. Through, such preliminary pilot tests, the researcher corrects the construct items and any noticed confusion in understanding of the items by the respondents. This is an opportunity for the questionnaire developer to know if there is any confusion about questionnaire items, and whether respondents have suggestions for possible improvements of the items. By administering a preliminary pilot test, the researcher can also get a rough idea on whether there is enough variation in the response to different items to justify moving ahead to large scale final pilot test. A preliminary pilot test should focus on important determinants of items including the feasibility of the design by checking whether the major number of respondents scored near zero or maximum score in a particular item to include it or reject it for the final stage. Researchers can modify the order of questions in the questionnaire along with adding or removing certain question items found appropriate during the reviewing process based on preliminary pilot test. This process of refining the questionnaire should be repeated several times until a satisfactory final draft of the questionnaire is prepared.

\section{FINAL QUESTIONNAIRE DEVELOPMENT THROUGH PILOT TESTING :}

Once the draft questionnaire finalized through preliminary pilot testing and subsequent revisions from experts is ready, the researcher can conduct a full-fledged pilot test among the intended respondents for initial validation. The pilot testing consists of administering the final version of the questionnaire to a considerable number of intended respondents. If the sample size of pilot test is small, then the possible errors may decrease the statistical power required to validate the questionnaire. In this stage, based on the intended statistical tests and validation on the collected pilot samples, the questionnaire can be refined further to a level which can minimize the statistical errors in the final solution.

\section{DETERMINING THE RELIABILITY OF QUESTIONNAIRE :}

The consistency of the survey results can be verified by checking the reliability of the questionnaire. Reliability testing also helps to determine errors present in content sampling, variations in demographical characteristics of respondents, choice and acceptance of score raters or measurement scales, etc. The consistency and hence reliability of a questionnaire can be determined and evaluated using its internal consistency, test-retest reliability, inter-rater reliability, parallel form reliability, and split-half reliability. A questionnaire-based survey is highly reliable if it produces the same result when repeated again under the same conditions. The following points are worth to consider :

(i) Reliability concerns in the questionnaire-based survey measurements provide stable and consistent result [26].

(ii) Reliability concerns repeatability of results obtained through systematic survey. The scale or test is said to be reliable if the same result is obtained for repeated measurements under the same conditions [27]. 
(iii) Reliability test is important in both survey-based and experiment-based research as it refers to the consistency in the result provided by the measuring instrument [28].

(iv) A measuring scale is considered as having high reliability and hence high internal consistency if every item of a scale supports to measure the same construct [28-29].

\subsection{Internal consistency :}

Internal consistency is a measure of the inter-correlation of the items of the questionnaire and hence the consistency in the measurement of intended construct. The commonly used method for measuring internal consistency is by calculating the Cronbach Alpha coefficient. According to this method, for a given questionnaire $\mathrm{x}$, with $\mathrm{k}$ number of items, the Cronbach's alpha $(\alpha)$ can be calculated as:

$\alpha=\frac{\kappa}{\kappa-1}\left(1-\frac{\sum \sigma_{i}^{2}}{\sigma_{x}^{2}}\right)$

In equation (1), $\sigma_{1}^{2}$ is the variance of item $i$, and $\sigma_{x}^{2}$ is the total variance of the questionnaire. For a given questionnaire, Cronbach's alpha value usually ranges from 0 to 1 and may sometimes be negative if some items are negatively correlated with other items in the questionnaire. In case if the Cronbach's alpha value is negative for a given questionnaire, the reverse scared items should be checked and modified as correctly scored items if required. Still if Cronbach's alpha takes a negative value then there is a serious problem in the design of the questionnaire and the researcher should relook into the format of the questionnaire intended to use for the survey.

The zero value of Cronbach's alpha indicates no internal consistency (i.e., no items in the questionnaire are correlated with one another). The increase in positive value of Cronbach's alpha above zero indicates that items are more strongly interrelated with one another. The value of Cronbach's alpha for a questionnaire is equal to one indicates perfect internal consistency (i.e., all the questionnaire items are perfectly correlated with each other).

According to expert suggestions, the Cronbach's alpha value is expected to be at least 0.70 to indicate adequate internal consistency of a given questionnaire. Low value (below 0.7 ) of Cronbach's alpha for a given questionnaire represents poor internal consistency and hence poor inter-relatedness between items. It is found that the value of Cronbach's alpha is a function of length of questionnaire (i.e., number of items in the questionnaire) and will increase its value with increase in length and hence number of items. Following table 3 gives an idea of the value of Cronbach's alpha, the internal consistency coefficient for a given questionnaire with the degree of reliability of the questionnaire.

Table 3 : The idea of the value of Cronbach's alpha with the degree reliability [29-31]

\begin{tabular}{|l|l|l|}
\hline S. No. & $\begin{array}{l}\text { Value of Cronbach's alpha } \\
(\boldsymbol{\alpha})\end{array}$ & Degree of Reliability \\
\hline 1 & $\alpha \leq 0$ & $\begin{array}{l}\text { A serious problem in the design of the questionnaire and } \\
\text { the researcher should relook into the format of the } \\
\text { questionnaire intended to use for the survey. } \\
\text { Low internal consistency and hence poor inter-relatedness } \\
\text { between items. Should be discarded or revised. }\end{array}$ \\
\hline 2 & $0<\alpha<0.5$ & $\begin{array}{l}\text { Moderate internal consistency and reliability of a given } \\
\text { questionnaire. Can be revised. }\end{array}$ \\
\hline 3 & $\alpha=0.7$ & $\begin{array}{l}\text { Adequate internal consistency and reliability of a given } \\
\text { questionnaire. }\end{array}$ \\
\hline 4 & $0.7<\alpha<0.9$ & $\begin{array}{l}\text { High internal consistency and reliability in a given } \\
\text { questionnaire. Can be revised. }\end{array}$ \\
\hline 5 & $0.9<\alpha<1.0$ & $\begin{array}{l}\text { Some questionnaire items may be redundant and the } \\
\text { researcher has to consider removing some items from the } \\
\text { questionnaire that are repeated questions in multiple ways. }\end{array}$ \\
\hline 6 & $\alpha=1.0$ & \begin{tabular}{l} 
Perfect internal consistency in a given questionnaire \\
\hline
\end{tabular}
\end{tabular}

It should be noted that the value of Cronbach's alpha depends on the responses from a specific set of respondents. Researchers have to keep in mind that under all circumstances Cronbach's alpha is not the 
estimate of reliability, but it only indicates the extent to which the questionnaire is reliable for a particular population of respondents. A questionnaire with excellent reliability with one set sample needs not have same amount reliability with another set of samples. Hence, the reliability of a questionnaire should be estimated every time when the questionnaire is administered to the respondents.

\subsection{Test-retest reliability :}

Test-retest reliability involves administering the questionnaire to the same group of respondents at different point of time and repeating the research. The results are then compared for similarity to decide the reliability. But this type of reliability test has limitation caused by memory effects. In this method, in the subsequent questionnaire administration, respondents may respond by remembering the previous answer which gives rise to artificial reliability. One of the techniques to reduce this kind of memory effect, the time between test and retest should be increased. In test-retest reliability test, if same individuals were administered the same questionnaires twice or more, the reliability can be evaluated using a correlation coefficient called Pearson's product moment correlation coefficient (Pearson's $r$ ) or the intraclass correlation coefficient [31]. Pearson's $r$, the correlation coefficient between the two questionnaire responses can be referred to as the coefficient of stability. Larger the coefficient stability, stronger the test-retest reliability and vice-versa. Test-retest reliability method is commonly used to measure the reliability of questionnaires which are specifically designed to measure personality traits, interest, or attitudes that are relatively stable across time, such as anxiety and pain catastrophizing. This method cannot be used for surveys which measure transitory attributes which change with time, such as pain intensity or recovery level of health-related problems. It is suggested that the time gap between test-retest should not be too short and too long to avoid the memory effect of respondents and as to allow changes to take place due to any other reason, respectively.

\subsection{Inter-rater reliability}

This method allows to examine a questionnaire for its reliability by means of multiple raters. Here, a questionnaire with multiple raters or scales is administered to the same group of respondents and evaluated. The consistency of evaluation is called as the inter-rater reliability. The inter-rater reliability of a questionnaire can be estimated using the kappa statistics. Accordingly, if two researchers independently rate the same group of patients on their mobility after surgery (e.g., $0=$ needs help of $2+$ people; $1=$ needs help of 1 person; $2=$ independent), kappa $(\kappa)$ can be computed as follows: $\kappa=\frac{P_{0}-P_{e}}{1-P_{e}}$

Where, $P_{o}$ is the observed proportion of observations in which the two raters agree, and $P_{e}$ is the expected proportion of observations in which the two raters agree by chance. Accordingly, $\kappa$ is the proportion of agreement between the two raters, after factoring out the proportion of agreement by chance. The value of kappa $(\kappa)$ ranges from 0 to 1 . Table 4 summarizes the value of kappa $(\kappa)$ and the degree of inter-rater reliability. An extension of Cohen's $\kappa$ statistics is available to determine inter-rater reliability in cases where more than two raters are used.

Table 4: The idea of the value of kappa $(\kappa)$ with the degree of inter-rater reliability [31]

\begin{tabular}{|l|l|l|}
\hline S. No. & Value of kappa $(\boldsymbol{\kappa})$ & Degree of inter-rater reliability \\
\hline 1 & $\kappa=0$ & Indicates no agreement between the two raters. \\
\hline 2 & $\kappa=0.01-0.20$ & Indicates poor agreement \\
\hline 3 & $\kappa=0.21-0.40$ & Indicates slight agreement \\
\hline 4 & $\kappa=0.41-0.60$ & Indicates fair agreement \\
\hline 5 & $\kappa=0.61-0.80$ & Indicates good agreement \\
\hline 6 & $\kappa=0.81-0.92$ & Indicates very good agreement \\
\hline 7 & $\kappa=0.93-1.0$ & Indicates excellent agreement \\
\hline 8 & $\kappa=1.0$ & $\begin{array}{l}\text { Indicates perfect agreement between the two } \\
\text { raters. }\end{array}$ \\
\hline
\end{tabular}




\subsection{Parallel form reliability}

In this method, a parallel form of questionnaire is developed which is equivalent to the original one with same information but different formatted questions (called as A and B). Both forms are used to collect the sample data during the survey. Respondents are requested to fill both forms of questionnaires during the same point of time. The correlations of the response of both forms estimates the reliability of the questionnaire by the assumption that these two forms are interchangeable. However, this method has limitations in terms of its enhanced expense on time and effort.

\subsection{Split-half reliability}

This method is developed to check whether the questions in the questionnaire are capable to measure the same underlying constructs as per the plan. In Split-half reliability measure model, the questions are split in two halves and then, the correlation of the scores on the scales from the two halves is calculated and is run through the Spearman Brown formula.

Performing a reliability test on a questionnaire is meaningful if and only it is combined with the validity test to check the validity of the questionnaire, as discussed in the next section.

\section{VALIDATING THE QUESTIONNAIRE :}

Validity test of a survey questionnaire is a process of analysing the survey questions for their dependability. Since there are many complex factors which can influence the dependability of a question in a questionnaire, validating a survey is a complex process. Validity of a questionnaire is determined by knowing what it is intended to measure. Validity explains how well the collected data cover the actual area of investigation [32]. Further, validation decides the validity of the inferences and conclusions made based on the results of the questionnaire.

The major types of validation tests commonly used while validating a questionnaire are (1) face validation, (2) content validation, (3) construct validation, and (4) criterion validation. There are six steps commonly used in the validation method of many empirical research methodologies. Figure 3 lists the various types and subtypes of various validity tests used in empirical research methodologies.

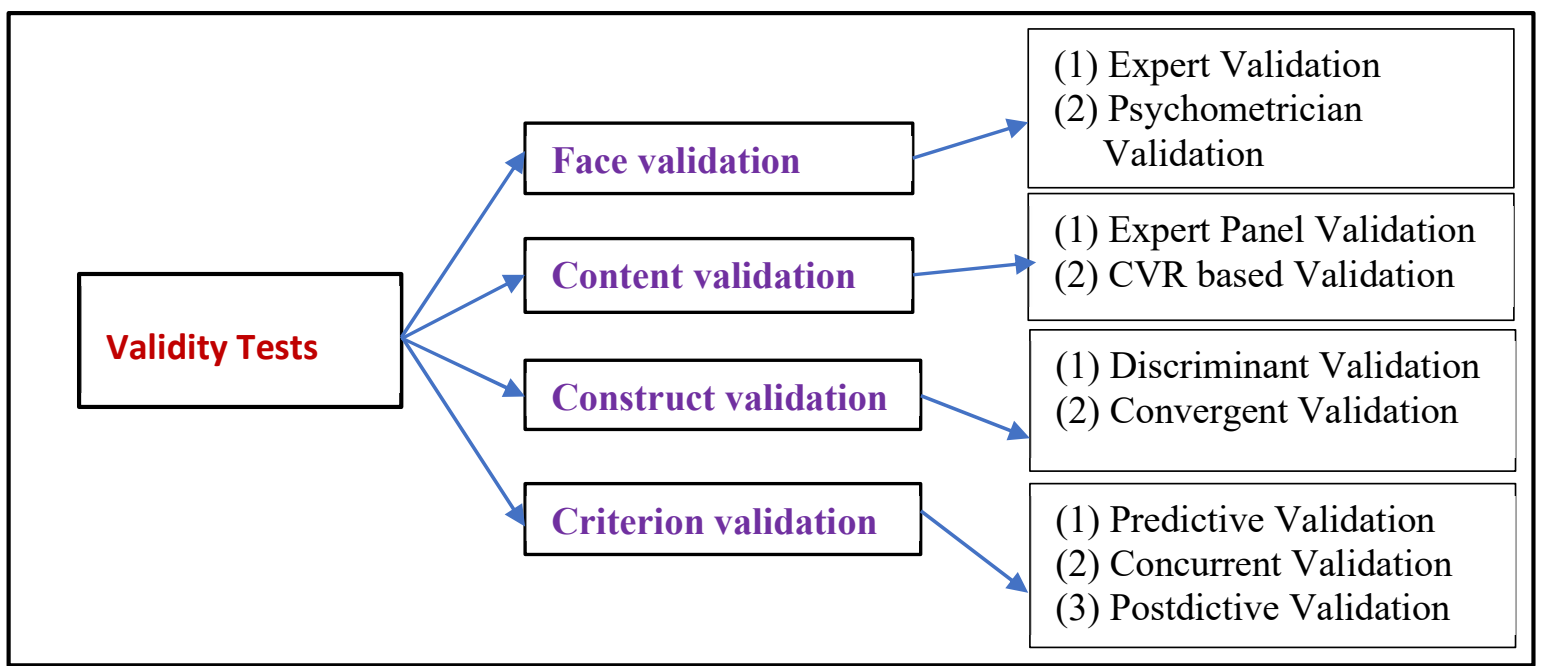

8.1 Face Validation :

Fig. 3 : Types and subtypes of Validity Tests.

It is the process of checking the questions in the questionnaire linguistically and analytically to find out what is supposed to be measured based on respondent's understanding of the questions in the questionnaire. In face validation, the researcher is requested to subjectively judge the operation of a construct used in the questionnaire. Face validity test is conducted with selected respondents to know how easily they understand the items/questions in the questionnaire, including its feasibility, style formatting, readability, clarity in language, etc. Thus, face validation confirms that the prepared questionnaire format and the presentation of items in it are relevant to be considered as measuring instrument and the items framed are reasonable, clear and unambiguous to understand and respond [33]. 
Face validation can be determined using dichotomous scale by using Yes and No options to indicate favourable or unfavourable items, respectively. Favourable items are objectively structured and positively classified under the thematic category. The face validation of the questionnaire instrument then can be determined using Cohen's Kappa Index on collected data. It is recommended by many researchers that the Kappa index value of above 0.6 can be acceptable for inter-rater agreement in the questionnaire [34]. Thus, while checking face validation, researcher can use both expert's assessment and Cohen's Kappa index values for a given questionnaire. Face validation is recommended in social science research, management research, and health science research.

\subsection{Content Validation :}

Content validation is a process of examining the contents of the items of the questionnaire to check whether they represent the entire theoretical construct of the designed model of the problem under consideration. Content validation can be started after development and reliability check of a questionnaire. Content validation is done by a panel of experts who have expertise with the construct of the questionnaire and capable to evaluate content validation. The content validation team checks the questionnaire items and their adequateness in measuring the constructs and to know whether the chosen items are sufficient to measure the variables in the domain. Various approaches on content validity are used by different expert teams, which include content validity ratio and content validation form. Many content validation decisions depend on the effectiveness of experts chosen in the committee. The content validation may include questions related to clarity and easiness of the items chosen, details on the problem area of chosen constructs, identification of any missed important items in the questionnaire, and identifying and removal of any questions which violate the privacy of respondents, etc. Thus, in general, content validation is used to evaluate the item questions related to a given construct of a problem by retaining essential and eliminating unessential questions in a given domain of problem. The content validation ratio (CVR) can be calculated using Lawshe's Method [35]. Accordingly, content validation ratio is a linear transformation of a proportional level of agreement on how many "experts" within a panel rate an item "essential" calculated in the following way:

$$
\mathrm{CVR}=\frac{n_{e}-\left(\frac{N}{2}\right)}{\frac{N}{2}}
$$

where CVR is the content validity ratio, $\mathrm{n}_{\mathrm{e}}$ is the number of expert panel members indicating "essential," and $\mathrm{N}$ is the total number of expert panel members. The final evaluation to retain the item based on the CVR depends on the number of panels. The critical values for Lawshe's content validity ratio are discussed in many research publications [35-36].

\subsection{Construct Validity :}

Construct is an important parameter in the research environment and the entire questionnaire is designed to measure one or more constructs that are related to the research problem under consideration. Validity of construct is important while evaluating a questionnaire that is developed with the purpose to measure that construct. Some constructs in the questionnaires are not directly measurable or observable like pain, taste, smell, etc. If the construct in the questionnaire is not validated, the analysis of the findings, the interpretation of the results, and the inferences to be drawn out of it may become difficult.

The construct validity includes evaluation of questionnaire by estimating the association of that construct with other variables in which it should be correlated positively or negatively. The commonly used procedure includes administering the developed questionnaire in hand along with another preexisting instrument/questionnaire that measure similar constructs to same group of respondents. Correlation matrices have to be developed to study the association patterns between two questionnaires to measure the same construct and individual questionnaires to measure different constructs. Construct validation is considered as small if the correlation coefficient observed is 0.1 . Construct validation is considered as moderate if the correlation coefficient observed is 0.3 . and construct validation is considered as large if the correlation coefficient observed is 0.5 . The construct validity depends on how well the researcher transformed a concept, idea, strategy, or behaviour as a construct into working reality. There are two components for construct validity. They are named as convergent validity and discriminant validity. 


\section{(1) Convergent Validity :}

It is a parameter refers to the degree to which the two constructs that are measured are related theoretically and are in fact related. This kind of parameters are used in behavioural science research including, management, social science, psychology, etc.

\section{(2) Discriminant Validity :}

It is the extent to which one static inferred variable differs from other variables in the questionnaire. Discriminant validity also called divergent validity refers to the inferred variable which has more variance than measurement errors or unmeasured external influences or other constructs within the conceptual framework.

The construct validity (both convergent and divergent) can be verified by means of factor analysis conducted using principal component analysis with varimax rotation method [37-38].

\subsection{Criterion Validity :}

Criterion validity also called concrete validity is a test related to the measurement of outcome of a questionnaire-based survey. Such test predicts the outcome (performance or behaviour) in another situation (like past, present, and future). Criterion validation is used to interpret the test scores as an alternative strategy. Criterion validity is divided into three types namely predictive validity, concurrent validity, and postdictive validity.

(1) Predictive Validity :

This is a measure of the ability of the questionnaire-based survey to predict accurately what it has to be supposed to predict. Performing a long-term validity study is a convenient way to establish predictive validity. Usually, predictive validity takes a long time and need fairly large size of samples to acquire meaningful aggregate data. Thus, predictive validity analyses the ability of questionnaire based survey to predict the things what it expected theoretically.

\section{(2) Concurrent Validity :}

It is a test to gather evidence for predicting the other outcomes. In concurrent validity, the researcher can measure previously established constructs using the developed questionnaire. In general, the validity test checks the operationalizability of the questionnaire to distinguish between groups which can be distinguishable theoretically.

\section{(3) Postdictive Validity :}

It is a type of validity test with criterions which have been administered in the past. It is a test determined by the degree to which the scores of a given test are related to the scores of already established test in the history.

\subsection{Standard Procedure for Validation :}

Dave Collingridge [39] outlined a six-step validation method which include:

(1) Step One : Check the Questionnaire by Face validation :

As mentioned in previous section, face validation is a process of checking the questionnaire for the representation of the intended research topic and common errors in items including leading, confusing, and repeated questions. It is a two-step process using two groups of experts. The first group checks the questionnaire for intended topic of survey and determines whether the questions are relevant to capture the intended research topic of the survey. The second group of experts called psychometricians checks for common errors, including leading, confusing, and repeated questions.

(2) Step Two : Pilot Test of the Questionnaire:

In this step, a pilot test of the survey has to be conducted using the developed questionnaire for a small group of respondents called subset of intended survey participants. Generally, a small group of $10 \%$ respondents consisting of all sub-categories are used for pilot study. This pilot study helps to remove irrelevant and weak questions.

(3) Step Three : Clean Collected Data:

The data collected from the pilot study should be cleaned by transforming the data on a spreadsheet and comparing the scores of individuals on positive phrased questions and negative phrased questions for checking consistency. Entering the collected responses from the questionnaire to a spreadsheet allows to clean the data. By one person read the values aloud and another entering them into the spreadsheet greatly reduces the risk of error. Once data is entered, the next step is to reverse code negatively phrased questions. This will allow the researcher to remove such individual 
respondents who answer inconsistently. This stage also allows to check data entry errors in the survey reports.

\section{(4) Step Four : Use Principal Component Analysis (PCA) :}

Principal component analysis, (PCA) is used to measure principle components in the questionnaire. PCA uses a process called factor loadings which determine common themes in questions which load into same factors and such questions can be combined. The number of factors loaded determines the number of elements the developed survey is measuring. The range of factor loading scale is usually between -1.0 to +1.0 and commonly accepted value is above \pm 0.6 . This step is a complex for new researchers and taking the help of experts is always suggested.

\section{(5) Step Five : Check Internal Consistency using Cronbach's Alpha :}

Internal consistency is a measure of the inter-correlation of the items of the questionnaire and hence the consistency in the measurement of intended construct. The commonly used method of measuring internal consistency is by calculating the Cronbach Alpha coefficient. The correlations between the questions that load on the same factor have to be checked for ensuring consistency of survey answers and reliability of survey questions. As shown in the previous section, the Cronbach Alpha coefficient for standard test range from 0 to 1.0 and the accepted value of internal consistency is at least 0.6 to 0.7 . If the Cronbach Alpha coefficient value for a question is below 0.6, the researcher can think of deleting such questions from the survey. This step is also complex and need experts' suggestions for new researchers.

\section{(6) Step Six : Revise the questions of the Survey if Needed :}

In this final stage of validation, the researcher can revise the question or delete it by running Principal component analysis (PCA) and Cronbach's Alpha methods. But if minor changes are made to the questions in this stage, then the researcher can go for the next step of final data collection after one round final revision. If any major changes are required in the questionnaire at this stage, then one more round of pilot resting and internal consistency checking has to be repeated before deciding the final version.

The above six steps are followed in standard practice of validation of a designed and developed questionnaire before using it for the final survey. Table 5 compiles a review of different validation types and important definitions.

Table 5 : Compiled version of Questionnaire-related terminology [25]

\begin{tabular}{|c|c|}
\hline Terminology & Definitions \\
\hline Construct & A model, idea, or theory that the researcher is attempting to assess (e.g., quality of postoperative recovery) \\
\hline Validity & The ability of a questionnaire to truly measure what it purports to measure \\
\hline Reliability & $\begin{array}{l}\text { Reliability or reproducibility is the ability of a questionnaire to produce the same results when administered at two different points of } \\
\text { time }\end{array}$ \\
\hline Content validity & $\begin{array}{l}\text { The extent to which a questionnaire measure includes the most relevant and important aspects of a concept in the context of a given } \\
\text { measurement application }\end{array}$ \\
\hline Face validity & The ability of an instrument to be understandable and relevant to the targeted population \\
\hline Construct validity & $\begin{array}{l}\text { The degree to which scores on the questionnaire measure relate to other measures (e.g., patient reported or clinical indicators) in a } \\
\text { manner that is consistent with theoretically derived a priori hypotheses concerning the concepts that are being measured }\end{array}$ \\
\hline Diagnostic validity & The accuracy of a questionnaire in diagnosing certain conditions (e.g., neuropathic pain) \\
\hline Known-group validity & $\begin{array}{l}\text { The ability of a questionnaire to be sensitive to differences between groups of patients that may be anticipated to score differently in } \\
\text { the predicted direction }\end{array}$ \\
\hline Criterion validity & The ability of a questionnaire to measure how well one measure predicts an outcome for another measure \\
\hline Concurrent validity & The association of an instrument with accepted standards \\
\hline Predictive validity & $\begin{array}{l}\text { The ability of a questionnaire to predict future health status or test results. Future health status is considered a better indicator than the } \\
\text { true value or a standard }\end{array}$ \\
\hline Internal consistency & The degree of the inter-relatedness among the items in a multi-item questionnaire measure. It is usually measured by Cronbach's alpha \\
\hline $\begin{array}{l}\text { Repeatability } \\
\text { (test-retest reliability) }\end{array}$ & $\begin{array}{l}\text { The ability of the scores of an instrument to be reproducible if it is used on the same patient while the patient's condition has not } \\
\text { changed (measurements repeated over time) }\end{array}$ \\
\hline Responsiveness & $\begin{array}{l}\text { The extent to which a questionnaire measure can detect changes in the construct being measured over time. It is applicable } \\
\text { only for questionnaires that are designed to assess changes in the construct within a short period of time }\end{array}$ \\
\hline
\end{tabular}

\subsection{Other Validation Tests :}

The validation steps described in the previous section is a general model, however, a researcher, based on his maturity in the subject, the subject of the topic of the survey, the variation in sample data, the background of the respondent, the type of analysis to be used, and the nature of the problem, can consider or develop new kinds of validation tests which have a suitable scale with the ability to 
discriminate between different issues and groups in the domain of the research problem. Ideally, the validation tests should support the researcher to have clearly defined outcomes where the changes in the domain under consideration are well known.

\section{SAMPLE SIZE :}

The most important aspect of any research study is the magnitude of the sample size. If the sample size is very large, it could waste the resources of the researcher and the organization and if the sample size is small, it could not be able to correctly represent the population under study. Therefore, it is very important to rightly estimate the sample size for the research under study. The factors associated with data required for the computation of sample size include:

(1) Magnitude of acceptable error (e) to provide the desired precision of measurement.

(2) Value associated with the desire confidence level $(Z)$ which states the degree of confidence interval taken in the population mean. It is a percentage or decimal value that tells how confident a researcher can be for his research. For example, if we want to be $96 \%$ confident that the estimated weight of the students in the class should be within $5 \mathrm{~kg}$, then the desired confidence level is $96 \%$.

(3) Variance which is the estimator of the standard deviation of the population $(\sigma)$. It investigates that how heterogeneous is the population.

Thus, the desired sample size $\mathrm{n}=(\mathrm{Z} . \sigma / \mathrm{e})^{2}$

Alternately, there are many other qualitative guidelines which include :

(1) $5: 1$ ratio scheme where respondents to questions ratio is $5: 1$. (here minimum 50 samples required for 10 item questionnaire).

(2) 10:1 ratio scheme where respondents to questions ratio is 10:1. (here minimum 100 samples required for 10 item questionnaire).

(3) 15:1 ratio scheme where respondents to questions ratio is 15:1. (here minimum 150 samples required for 10 item questionnaire).

(4) 30:1 ratio scheme where respondents to questions ratio is 30:1. (here minimum 300 samples required for 10 item questionnaire).

Another qualitative general model suggests that a sample size of 50 is considered as very poor, sample size of 100 is considered as poor, a sample size of 200 is considered as fair, a sample size of 300 is considered as good, a sample size of 500 as very good, and the sample size of 1000 or more as excellent irrespective of the number of questions in the questionnaire. Thus, there are no fixed rules for use of sample size for a questionnaire for validation, but it is suggested to use sample size as large as possible to have higher respondents to question ratio [40-41].

\section{OTHER CONSIDERATIONS :}

After developing a suitable questionnaire and determining its reliability and validity, the researcher should consider other procedures related to permissions and regulations connected to that empirical research. These permissions and regulations may be different in different countries, institutions, and subject areas. If the sample collection is from employees or people belonging to a particular organization or particular community, the necessary permissions must be taken from the head of the organization or community before distributing the questionnaire. Similarly, the researchers are suggested to consult the ethical committee of research of their organization regarding necessary approvals needed to collect and use of such empirical data for further analysis and publication of results as research outcomes.

\section{STATISTICAL SOFTWARE USED FOR VALIDATION :}

The validity of various analytical methods must be done using statistical analysis of data to find the relationship between variables, patterns, and trends in the process of solving a problem. The statistical analysis essential for the interpretation of the analytic method validation includes calculation of mean, standard deviation, relative standard deviation, confidence intervals, and regression analysis. Some of the statistical tools used for empirical research include F-test, t-test, and regression analysis, correlation analysis, standard deviation, relative standard deviation, confidence interval, hypothesis testing, analysis of variation (ANOVA), design of experiments, and assessment of outliers. Two types of statistical techniques are used for statistical data analysis. They are called descriptive statistics and 
inferential statistics. Descriptive statistics organizes data by indexing the sample and Inferential statistics allows to draw a conclusion from random variant data.

Various statistical software packages are used for this purpose, which include proprietary software and open access software. Table 6 lists some of the commonly used proprietary statistical software packages and Table 7 lists some of the popular open access statistical software packages.

Table 6: List of commonly used proprietary statistical software packages

\begin{tabular}{|l|l|l|}
\hline S. No. & Package & Features \& Suppliers \\
\hline 1 & IBM SPSS & $\begin{array}{l}\text { https://www.ibm.com/analytics/spss-statistics- } \\
\text { software }\end{array}$ \\
\hline 2 & MaxStat & https://maxstat.de/en/home-en/ \\
\hline 3 & SAS & https://www.sas.com/en_in/home.html \\
\hline 4 & Stata & https://www.stata.com/statamp/ \\
\hline 5 & XL STAT & https://www.xlstat.com/en// \\
\hline 6 & Statwing & https://www.statwing.com/ \\
\hline 7 & NCSS & https://www.ncss.com/ \\
\hline 8 & AcaStat & https://acastat.com/ \\
\hline 9 & WizardMac & https://www.wizardmac.com// \\
\hline 10 & MINITAB & http://www.minitab.com/en-us/ \\
\hline
\end{tabular}

Table 7 : List of some popular open access statistical software packages

\begin{tabular}{|c|c|c|}
\hline S. No. & Package & Features \& Suppliers \\
\hline 1 & ADaMSoft & $\begin{array}{l}\text { Used for linear regression, cluster analysis, correspondence } \\
\text { analysis, data editing, data mining, record linkage methods } \\
\text { logistic regression, }\end{array}$ \\
\hline 2 & $\begin{array}{l}\text { Bayesian Filtering } \\
\text { Library }\end{array}$ & $\begin{array}{l}\text { Used for gridbased systems, kaman filtering, sequential } \\
\text { Monte Carlo methods, particle filters, and moisture filters }\end{array}$ \\
\hline 3 & CBEcon & $\begin{array}{l}\text { Used for descriptive statistics, T-tests, ANOVA, } \\
\text { regression, measures of association, probability } \\
\text { distribution, multivariate regression analysis, etc. }\end{array}$ \\
\hline 4 & $\begin{array}{l}\text { Intrinsic Noise } \\
\text { Analyser (INA) }\end{array}$ & $\begin{array}{l}\text { Used for studying reaction kinetics in chemistry and } \\
\text { biology. INA analyses mathematical models of intracellular } \\
\text { reaction kinetics in biology to quantify fluid concentration } \\
\text { fluctuations. }\end{array}$ \\
\hline 5 & Mondrian & Interactive data visualization tools. \\
\hline 6 & Pandas & Used for data manipulation and analysis \\
\hline 7 & Shogun (toolbox) & $\begin{array}{l}\text { Used as a statistical analysis tool for research and education } \\
\text { systems }\end{array}$ \\
\hline 8 & R Programming & General purpose package for statistical functions \\
\hline 9 & GNU PSPP & $\begin{array}{l}\text { Used for descriptive statistics, T-tests, ANOVA, regression, } \\
\text { measures of association, reliability and factor analysis, } \\
\text { cluster analysis, non-parametric tests, etc. }\end{array}$ \\
\hline 10 & MaxStat Lite Version & $\begin{array}{l}\text { F-test, t-test, and regression analysis, correlation analysis, } \\
\text { standard deviation, relative standard deviation, confidence } \\
\text { interval, hypothesis testing, analysis of variation (ANOVA), }\end{array}$ \\
\hline 11 & Salstat & All statistical tools \\
\hline
\end{tabular}




\section{VALIDATING EXPERIMENTAL DATA :}

Validation of experimental data needs a different set of procedures to maintain their reliability and consistency. This includes the following steps.

(1) Selectivity \& Repeatability :

Selectivity and repeatability are quantitative indications of how much the experimental method used to collect the data represents the signals of actual experiments without external interface and its ubiquitous repeatability. Any kind of external random interface should be determined by running the same experiment using blank samples with the same experimental conditions before and after running the experiment with actual samples. Based on calculating percent recovery and repeatedness, one can conclude that there is no interference of excipients and external additives to prove the selectivity and repeatability of the experimental method adopted.

(2) Data Accuracy :

Data accuracy refers to how accurate the value of data collected in an experiment. This can be determined by knowing the closeness of agreement between the actual value of individual data and the mean result obtained for a large number of homogeneous samples in a similar experimental procedure. To improve the data accuracy, a systematic error and data recovery procedure can be used to avoid errors by using appropriately certified reference samples or by using alternative analytical techniques.

(3) Experimental Precision :

To maintain experimental precision, the researcher must compare the results obtained from the samples used for the experiment for the repeatability \& reproducibility of the result under the same operating conditions over a short interval of time. Repeatability expresses the precision of measurement within the laboratory variations like : different temperatures, different time, different instruments, different analysts, different physical conditions, etc. Repeatability \& reproducibility leading to experimental precision decides the quality of experimental data. By repeating the same experiments in different laboratories using a standardized methodology for the same sample or at the same concentration of the sample and the comparative results should be expressed in the form of standard deviation.

(4) Instrument Detection limit :

Various techniques to determine instrument detection limit involve visual inspection, resolving power, signal to noise ratio, response time, standard deviation of response and its slope. The report on data collection should contain the limitation of detection and the method used to determine the detection limit.

(1) In the visual inspection method, the instrument is examined for its appropriateness in terms of making measurements. It should also ensure that the measurement errors based on scales used are minimum within the acceptable value.

(2) The resolving power of an instrument can be evaluated by knowing the inverse of the distance between two objects which can be just resolved when viewing through the used instrument.

(3) In signal-to-noise ratio method is to be used, the measured signals from samples should be compared with the known low concentration of the sample with those of blank solution.

(4) If the limit of detection based on the response has to be calculated, the standard deviation of the response time of instrument (s) and slope (S) of the calibration curve has to be determined.

(5) Instrument Quantitation limit :

A quantitation limit refers to the minimum amount or concentration of sample that can be measured within specified limits of precision and accuracy. Quantitation limit of an instrument is generally 5-10 times the instrument detection limit. The instrument quantization limit is expressed in terms of precision and accuracy of readings for arbitrarily non-zero low standard in the calibration curve. The data collection report should contain the quantitation limit and the method used to determine it.

(6) Sensitivity of an instrument :

Sensitivity of an instrument is a measure of the change in its response corresponding to change in sample properties (like size or concentration). Sensitivity of an instrument corresponding to the gradient of the response curve and has a linear relationship with size or concentration.

(7) Robustness :

Robustness of an instrument is the degree to which the instrument can function correctly in the presence of invalid inputs or stressful environmental conditions. Robustness test provides important information for the evaluation of the measurement uncertainty. 


\section{CONCLUSION :}

A simple and authentic set of guidelines is provided through this systematic review, on how to design, develop, reliability test, and validation test to translate a draft questionnaire into a usable questionnaire in social science, business management, and health science research. The format of the questionnaire with the meaning and appropriateness of the questions has to be tested and improved by means of checking the reliability and validity using internal and external experts. Validation of the questionnaire helps researchers to avoid wrong data collection and analysis, leading to a wrong interpretation of results. After developing a questionnaire, the researcher should validate it by conducting a pilot test and conclude that the questions in the questionnaire are correctly understandable and interpretable by the intended respondents while administering the questionnaire for the survey. Similarly, the validation of experimental data also important for the repeatability of the results, interpretation, and use of experimental results for applications. Hence, validation is an essential part of systematic research both in empirical and experimental research. In empirical research, the validation process ensures that the questionnaire is psychometrically rich to be used for authentic research. In experimental research, the validation of experimental data needs a different set of procedures to maintain their reliability and consistency. In this paper, the procedure of validation of the questionnaire of empirical research methods and the data to be obtained from scientific instruments in experimental research methods are reviewed for efficient and effective use of data collected for analysis and interpretation.

\section{REFERENCES :}

[1] Kothari, C. R. (2004). Research methodology: Methods and techniques. New Age International.

[2] Choy, L. T. (2014). The strengths and weaknesses of research methodology: Comparison and complimentary between qualitative and quantitative approaches. IOSR Journal of Humanities and Social Science, 19(4), 99-104.

[3] Warwick, D. P., \& Lininger, C. A. (1975). The sample survey: Theory and practice. McGraw-Hill.

[4] Rossi, P. H., Wright, J. D., \& Anderson, A. B. (Eds.). (2013). Handbook of survey research. Academic Press.

[5] Raghunathan, T. E., \& Grizzle, J. E. (1995). A split questionnaire survey design. Journal of the American Statistical Association, 90(429), 54-63.

[6] Ballinger, C., \& Davey, C. (1998). Designing a questionnaire: An overview. British Journal of Occupational Therapy, 61(12), 547-550.

[7] Bee, D. T., \& Murdoch-Eaton, D. (2016). Questionnaire design: the good, the bad and the pitfalls. Archives of Disease in Childhood-Education and Practice, 101(4), 210-212.

[8] Oosterveld, P., Vorst, H. C., \& Smits, N. (2019). Methods for questionnaire design: a taxonomy linking procedures to test goals. Quality of Life Research, 28(9), 2501-2512.

[9] Kachroo, P., \& Kachen, S. (2018). Item placement for questionnaire design for optimal reliability. Journal of Marketing Analytics, 6(4), 120-126.

[10] Sirakaya-Turk, E., \& Uysal, M. S. (2017). Survey research: sampling and questionnaire design. Research methods for leisure, recreation and tourism, (Ed. 2), 122-146.

[11] Moroney, W. F., \& Joyce, A. (2019). Questionnaire Design: How to Ask the Right Questions of the Right People at the Right Time to Get the Information You Need. ergonomics in design. ISBN: 978-0-945289-56-2.

[12] Yaddanapudi, S., \& Yaddanapudi, L. N. (2019). How to design a questionnaire. Indian journal of anaesthesia, 63(5), 335.

[13] Riaño, C. E., \& Palomino, M. (2015). Design and preparation of a questionnaire according to Delphi method to select virtual laboratories (VL). Sophia, 11(2), 129-141. 
[14] Bovell-Benjamin, A. C., Dawkin, N., Pace, R. D., \& Shikany, J. M. (2009). Use of focus groups to understand African-Americans' dietary practices: Implications for modifying a food frequency questionnaire. Preventive medicine, 48(6), 549-554.

[15] Peytchev, A., \& Peytcheva, E. (2017, December). Reduction of measurement error due to survey length: Evaluation of the split questionnaire design approach. In Survey Research Methods, 11(4), 361-368).

[16] de Jong, J. A., Dorer, B., Lee, S., Yan, T., \& Villar, A. (2018). Overview of Questionnaire Design and Testing. Advances in Comparative Survey Methods: Multinational, Multiregional, and Multicultural Contexts (3MC), 115.

[17] Hamed Taherdoost (2016). Sampling Methods in Research Methodology; How to Choose a Sampling Technique for Research. International Journal of Academic Research in Management (IJARM), 5(2), 28-36.

[18] Onwuegbuzie, A. J., Dickinson, W. B., Leech, N. L., \& Zoran, A. G. (2009). A qualitative framework for collecting and analyzing data in focus group research. International journal of qualitative methods, 8(3), 1-21.

[19] Aithal, P. S., Shailashree, V., \& Kumar, P. M. (2016). Factors \& Elemental Analysis of Six Thinking Hats Technique Using ABCD Framework. International Journal of Advanced Trends in Engineering and Technology (IJATET), 1(1), 85-95.

[20] Aithal, P. S. (2016). Review on Various Ideal System Models Used to Improve the Characteristics of Practical Systems. International Journal of Applied and Advanced Scientific Research, 1(1), 47-56. DOI: http://doi.org/10.5281/zenodo.159749.

[21] Aithal, P. S., \& Aithal, Shubhrajyotsna (2019). New Directions in Scholarly Research- Some Fearless Innovations \& Predictions for 21st Century Research. International Journal of Management, Technology, and Social Sciences (IJMTS), 4(1), 1-19. DOI: https://doi.org/10.5281/zenodo.2557222.

[22] Aithal, P. S., Shailashree, V. T., Suresh Kumar, P. M. (2015). A New ABCD Technique to Analyze Business Models \& Concepts. International Journal of Management, IT and Engineering (IJMIE), 5(4), 409 - 423. DOI : http://doi.org/10.5281/zenodo.61652.

[23] Aithal, P. S. (2016). Study on ABCD Analysis Technique for Business Models, business strategies, Operating Concepts \& Business Systems. International Journal in Management and Social Science, 4(1), 98-115. DOI : http://doi.org/10.5281/zenodo.161137.

[24] Aithal P. S. \& Shubhrajyotsna Aithal (2018). Factor \& Elemental Analysis of Nanotechnology as Green Technology using ABCD Framework. International Journal of Management, Technology, and Social Sciences (IJMTS), 3(2), 57-72. DOI : https://doi.org/10.5281/zenodo.1451490.

[25] Lewis, S. (2015). Qualitative inquiry and research design: Choosing among five approaches. Health promotion practice, 16(4), 473-475.

[26] Carmines E. G. \& Zeller, R. A. (1979). Reliability and Validity Assessment, Newbury Park, CA, SAGE.

[27] Moser C. A. \& Kalton, G. (1989). Survey methods in social investigation, Aldershot, Gower.

[28] Huck, S. W. (2007). Reading Statistics and Research, United States of America, Allyn \& Bacon.

[29] Robinson, W. S. (2009). Ecological correlations and the behavior of individuals. International journal of epidemiology, 38(2), 337-341.

[30] Straub, D., Boudreau, M. C., \& Gefen, D. (2004). Validation guidelines for IS positivist research. Communications of the Association for Information systems, 13(1), 380-427.

[31] Hamed Taherdoost. (2016). Validity and Reliability of the Research Instrument; How to Test the Validation of a Questionnaire/Survey in a Research. International Journal of Academic Research in Management (IJARM), 5(3), 28-36. 
[32] Ghauri, P. \& Gronhaug, K. (2005). Research Methods in Business Studies, Harlow, FT/Prentice Hall.

[33] Oluwatayo, J. A. (2012). Validity and reliability issues in educational research. Journal of educational and social research, 2(2), 391-400.

[34] Gelfand, D. M., Hartmann, D. P., Cromer, C. C., Smith, C. L., \& Page, B. C. (1975). The effects of instructional prompts and praise on children's donation rates. Child Development, 46, 980-983.

[35] Lawshe, C. H. (1975). A quantitative approach to content validity. Personnel psychology, 28(4), 563-575.

[36] Ayre, C., \& Scally, A. J. (2014). Critical values for Lawshe's content validity ratio: revisiting the original methods of calculation. Measurement and Evaluation in Counseling and Development, 47(1), 79-86.

[37] Brown, S. M., McBride, G., Collingridge, D. S., Butler, J. M., Kuttler, K. G., Hirshberg, E. L., ... \& Orme, J. (2015). Validation of the Intermountain patient perception of quality (PPQ) survey among survivors of an intensive care unit admission: a retrospective validation study. BMC health services research, 15(1), 1-7.

[38] Hamed Taherdoost (2016). Validity and Reliability of the Research Instrument; How to Test the Validation of a Questionnaire/Survey in a Research. International Journal of Academic Research in Management (IJARM), 5(3), 28-36.

[39] Collingridge, D. S., \& Gantt, E. E. (2008). The quality of qualitative research. American journal of medical quality, 23(5), 389-395.

[40] MacCallum, R. C., Widaman, K. F., Zhang, S., \& Hong, S. (1999). Sample size in factor analysis. Psychological methods, 4(1), 84.

[41] Malterud, K., Siersma, V. D., \& Guassora, A. D. (2016). Sample size in qualitative interview studies: guided by information power. Qualitative health research, 26(13), 1753-1760. 